\title{
Effects of larval diets on flight capacity and flight fuel in adults of the common cutworm, Spodoptera litura (Lepidoptera: Noctuidae)
}

\author{
Rie Sakamoto, ${ }^{\dagger}$ Mika Murata ${ }^{\ddagger}$ and Sumio ToJo* \\ Department of Applied Biological Sciences, Faculty of Agriculture, Saga University; Saga 840-8502, Japan \\ (Received 30 June 2003; Accepted 16 October 2003)
}

\begin{abstract}
The last instar larvae of Spodoptera litura were reared on soybean leaves (SL), eddo leaves (EL), an artificial diet $(A D)$, or $A D$ supplemented with soybean oil $(A D+O)$. Larvae fed on SL developed faster into adults with smaller sizes and lower levels of triacylglycerol (TG) than those from the $\mathrm{AD}$ or $\mathrm{AD}+\mathrm{O}$ groups. The ratio of $\mathrm{C} 18$ unsaturated fatty acids in the TG fatty acids was similar (nearly 40\%) among the adults of these three groups, as was the average total flight duration of about $6 \mathrm{~h}$ tested over $20 \mathrm{~h}$ of tethered flight. The ratio of $\mathrm{C} 18$ unsaturated fatty acids in the TG fatty acids tended to decline with longer tethered flight in the adults of these three groups. On the other hand, the development of individuals from EL was greatly retarded and they emerged as the smallest adults with the lowest level of abdominal TG with essentially no C18 unsaturated fatty acids in the TG. Adults from EL could barely fly when tested in tethered flight. These results support the notion that the flight capacity of S. litura depends greatly on the plants eaten as larvae and the C18 unsaturated fatty acids in the TG function as the major flight fuel.
\end{abstract}

Key words: Flight fuel; flight capacity; unsaturated fatty acid; food plant; migration

\section{INTRODUCTION}

It is generally expected that nutrient uptake during the larval period influences the reproductive and flight capacity of adult insects, especially of those who reproduce shortly after emergence. Much work has been published on the effects of larval nutrient uptake on adult reproductive ability (Awmack and Leather, 2002), but only a few studies have been done on the influences on adult flight capability (Harrison, 1980; Slansky and Scriber, 1985).

Adult moths of the common cutworm, Spodoptera litura Fabrius are thought to migrate overseas because males have been caught on weather-forecasting ships on oceans (Asahina and Turuoka, 1968) and the sudden and coincidental occurrence of them has often been recorded in different areas $180 \mathrm{~km}$ apart at the time of approach of a typhoon (Murata et al., 1998) and at the time of arrival at these sites of spring and autumn rain fronts (Murata et al., unpublished).

It has been accepted that in long-distance migratory insects, triacylglycerol (TG), the neutral lipid, is used as the major flight fuel (Beenakkers et al., 1985: Blacklock and Ryan, 1994). In another study (Murata and Tojo, in press) we demonstrated that sexually mature adults of $S$. litura can fly nearly $24 \mathrm{~h}$ in tethered flight, and that TG levels decrease with longer periods of flight nearly coinciding with the decline of the unsaturated fatty acid ratio in the TG fatty acids (TG's). It was also shown that TG levels and fore-wing sizes in newly emerged $S$. litura adults decline with decreasing food quality of an artificial diet taken during the last larval instar (Itoyama et al., 1999).

The larvae of $S$. litura are known to eat more than 77 varieties of plant food (Okamoto and Okada, 1968). Our observations suggest that, in Kyushu, they prefer eddos in summer, but soybeans in autumn.

Using this information, we here compare the developmental traits, adult TG and flight capacity by rearing last instar larvae of $S$. litura on four different diets including eddo and soybean leaves, and demonstrate that these parameters are greatly influenced by the larval food plants.

\footnotetext{
* To whom correspondence should be addressed at: E-mail: tojos@cc.saga-u.ac.jp

$\dagger$ Present address: Biological Research Department, Odawara Research Center, Odawara, Kanagawa 250-0280, Japan

¥ Present address: Department of Biology, Faculty of Science and Engineering, Konan University, Kobe, Hyogo 658-8501, Japan
} 


\section{MATERIALS AND METHODS}

Insects. Eggs of S. litura were kindly supplied by Sumitomo Chemical Co., Ltd. and their progeny were reared at $25^{\circ} \mathrm{C}$ under a $16 \mathrm{~h} \mathrm{~L}-8 \mathrm{~h}$ D photoregime for several generations on an artificial diet composed mostly of kidney beans, wheat germ and yeast powder (Okamoto and Okada, 1968). For the experiment, males were used. All of the larvae before the ecdysis to the sixth (last) larval instar were reared on the artificial diet under the same conditions for stock culture. Fifty newly-molted last-instar larvae were then transferred to each of four containers $(23 \mathrm{~cm} \times 33 \mathrm{~cm}, 6 \mathrm{~cm} \mathrm{~h})$ where they were reared on one of the following diets: the artificial diet as mentioned above (AD); the diet supplemented with soybean oil (final concentration, $0.3 \mathrm{~g} / \mathrm{kg})(\mathrm{AD}+\mathrm{O})$; eddo, Colocasia esculenta var. antiquorum (variety: Akaimo) leaves (EL); or soybeans, Glycine max (variety: Murayutaka) leaves (SL). Their development profiles to adults were compared under the same laboratory conditions. Adult emergence was checked every $8 \mathrm{~h}$ and, to ensure that no flight energy source was wasted, each adult was maintained in a test tube $(1.2 \mathrm{~cm}$ i.d., $10.5 \mathrm{~cm} \mathrm{~h}$ ) with a piece of filter paper moistened with water that was exchanged every other day until the flight experiment.

Tethered flight. Three-day-old male moths (72-80 h after emergence) were used for the tethered flight experiment for a maximum of $20 \mathrm{~h}$, as described in another paper (Murata and Tojo, in press). Briefly, the flights of ten moths were measured for each set of experiments, recorded for $2 \mathrm{~s}$ every $30 \mathrm{~s}$ by a video camera, and the flying times of each moth were later counted by eye from the video film to obtain the total flight duration. If an adult did not start flying during the first $30 \mathrm{~min}$, the leg was briefly touched with a small brush to instigate the flying. After flight, the abdomen was cut from the moth, frozen at $-20^{\circ} \mathrm{C}$, lyophilized within a week and stored at $-20^{\circ} \mathrm{C}$ for lipid analysis. TG levels and fatty acid composition in the samples were determined as previously described (Itoyama et al., 1999).

\section{RESULTS}

Effects of different diets taken by last instar larvae on development and adult characteristics

The fatty acids in the soybean oil used in the present study were composed of $40 \%$ linoleic acid (C18:2), 18\% oleic acid (C18:1) and 4\% linolenic acid (C18:3) (data for others not shown). The artificial diet with added soybean oil $(\mathrm{AD}+\mathrm{O})$ apparently contained higher levels of total fatty acids and a higher ratio of these $\mathrm{C} 18$ unsaturated fatty acids, compared with AD (Fig. 1). The level of total fatty acids was similar between soybean leaves (SL) and eddo leaves (EL) and their composition did not differ greatly between them, linolenic acid being predominant among the unsaturated fatty acids (Fig. 1).

The last instar larvae were reared on these four different diets and their developmental profiles to adult emergence were compared under the same temperature and photo-regime conditions. The development of the individuals fed on EL was greatly retarded, as reflected in the smallest maximum larval weight, longest last larval instar and pupal duration, and lowest emergence ratio among the four groups fed on different diets (Table 1). Adults from

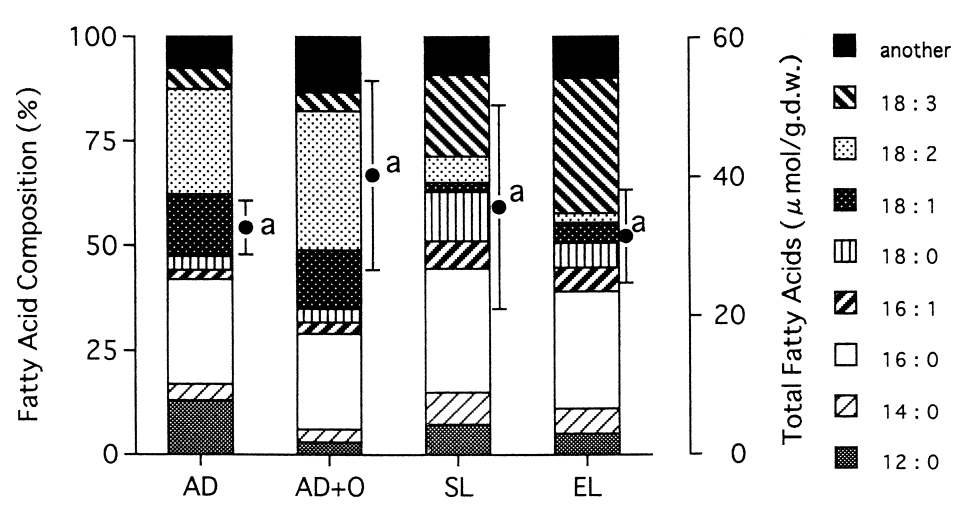

Fig. 1. Comparison of total fatty acid content and fatty acid composition $(N=3-5)$ in four diets fed to last instar larvae of $S$. litura. AD: artificial diet; $\mathrm{AD}+\mathrm{O}$ : artificial diet supplied with soybean oil $(0.03 \% \mathrm{w} / \mathrm{w})$; SL: soybean leaves; EL: eddo leaves. 
Table 1. Comparison of development traits of $S$. litura males, which were fed four different diets during the last larval instar ${ }^{\mathrm{a}}$

\begin{tabular}{lccrc}
\hline \multicolumn{1}{c}{ Diet } & $\begin{array}{c}\text { The maximum wet } \\
\text { weight }(\mathrm{mg} \pm \mathrm{SD} \text { ) }\end{array}$ & $\begin{array}{c}\text { Last larval stadium } \\
\text { duration (days } \pm \text { SD) }\end{array}$ & $\begin{array}{c}\text { Pupal duration } \\
\text { (days } \pm \text { SD) }\end{array}$ & $\begin{array}{c}\text { Percentage of adult } \\
\text { emergence }(\%)\end{array}$ \\
\hline Artificial diet (AD) & $868.3 \pm 59.2 \mathrm{a}$ & $5.0 \pm 0.3 \mathrm{a}$ & $11.0 \pm 0.9 \mathrm{a}$ & 82 \\
AD+soybean oil (O) & $885.5 \pm 68.5 \mathrm{a}$ & $4.2 \pm 0.2 \mathrm{~b}$ & $10.1 \pm 0.7 \mathrm{~b}$ & 78 \\
Soybean leave (SL) & $788.7 \pm 41.5 \mathrm{~b}$ & $4.2 \pm 0.2 \mathrm{~b}$ & $9.1 \pm 0.7 \mathrm{c}$ & 94 \\
Eddo leave (EL) & $616.8 \pm 53.6 \mathrm{c}$ & $7.9 \pm 0.8 \mathrm{c}$ & $15.9 \pm 1.1 \mathrm{~d}$ & 52 \\
\hline
\end{tabular}

${ }^{a}$ Values followed by different characters are significantly different $(p<0.01$, Bonferroni/Dunn, $N=11-20)$.

${ }^{\mathrm{b}}$ The maximum weight of the final instar larva.

Table 2. Morphometrical characteristics of $S$. litura male adults, which were fed different diets during the last larval instar ${ }^{\mathrm{a}}$

\begin{tabular}{lccc}
\hline \multicolumn{1}{c}{ Diet } & $\begin{array}{c}\text { Wet weight of } \\
\text { adult }(\mathrm{mg} \pm \mathrm{SD})\end{array}$ & $\begin{array}{c}\text { Forewing length } \\
(\mathrm{mg} \pm \mathrm{SD})\end{array}$ & $\begin{array}{c}\text { Loading index of } \\
\text { wing }(\mathrm{mg} / \mathrm{mg} \pm \mathrm{SD})\end{array}$ \\
\hline Artificial diet (AD) & $169.6 \pm 10.2 \mathrm{a}$ & $17.9 \pm 0.7 \mathrm{a}$ & $0.55 \pm 0.08 \mathrm{a}$ \\
AD+soybean oil (O) & $160.8 \pm 17.8 \mathrm{ab}$ & $16.3 \pm 0.7 \mathrm{~b}$ & $0.60 \pm 0.04 \mathrm{a}$ \\
Soybean leave (SL) & $146.4 \pm 11.4 \mathrm{bc}$ & $15.5 \pm 0.5 \mathrm{c}$ & $0.62 \pm 0.04 \mathrm{a}$ \\
Eddo leave (EL) & $115.5 \pm 21.4 \mathrm{c}$ & $14.2 \pm 0.6 \mathrm{~d}$ & $0.58 \pm 0.15 \mathrm{a}$ \\
\hline
\end{tabular}

${ }^{a}$ Values followed by different characters are significantly different $(p<0.01$, Bonferroni/Dunn, $N=4-9)$.

EL had the smallest size with the shortest wing (Table 2). Individuals fed on SL developed to adults faster than those from $\mathrm{AD}$ or $\mathrm{AD}+\mathrm{O}$. They emerged to adults with the highest survival ratio (Table 1), and tended to be smaller than those fed on the artificial diets, although their wing loading index did not differ from the others (Table 2).

\section{Effects of different diets taken by last instar lar- vae on adult flight capacity, TG and its fatty acid composition}

When male adults derived from the larvae fed on $\mathrm{AD}, \mathrm{AD}+\mathrm{O}$, or SL diets were kept only on water for three days after emergence and then tested for a maximum of $20 \mathrm{~h}$ using tethered flight, the total flight duration was, on average, almost the same, ca six hours among these three groups, although the values fluctuated greatly. For example, one male from $\mathrm{AD}$ flew $12 \mathrm{~h}$ while some others could only fly for one hour (Fig. 2). While most of the males from EL could not fly, three individuals less than three hours $(N=13)$ (Fig. 2).

In three-day-old non-fed males, the average abdominal TG content per gram of dry weight was highest in the males from $\mathrm{AD}+\mathrm{O}(1,360 \mu \mathrm{mol})$, followed by those from $\mathrm{AD}(900 \mu \mathrm{mol})$ and then those from SL $(410 \mu \mathrm{mol})$, but the content was un-

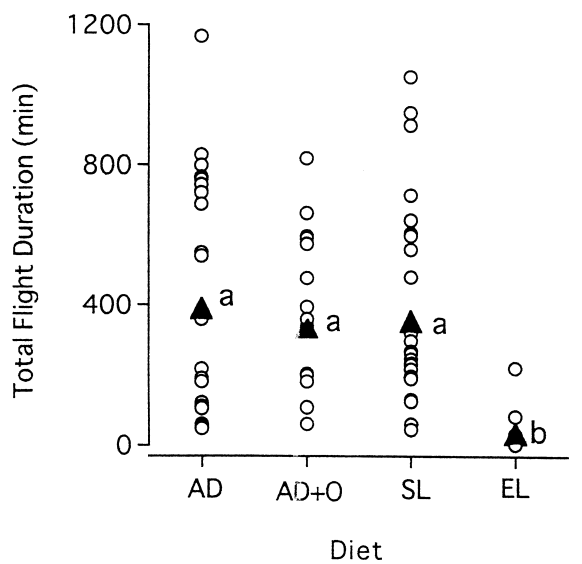

Fig. 2. Comparison of total flight duration during tethered flight for a maximum of $20 \mathrm{~h}$ in S. litura males, which were fed during the last larval instar on one of four diets (see Fig. 1) as given on the abscissa. The males were maintained separately without food for three days after emergence and then used for the experiment. Closed triangles (average values) with different letters are significantly different $(p<0.05, U$-test $)$.

expectedly low in those from EL $(80 \mu \mathrm{mol})$ (Fig. 3 ). When three-day-old non-fed males were flown for nine hours, the ratio of $\mathrm{C} 18$ unsaturated fatty acids in their abdominal TG's declined from 44\% before flight to $31 \%$ in those from $\mathrm{AD}$ and similarly for those from $\mathrm{AD}+\mathrm{O}$ (from $40 \%$ to $33 \%$ ). Oleic acid was the predominant unsaturated fatty 


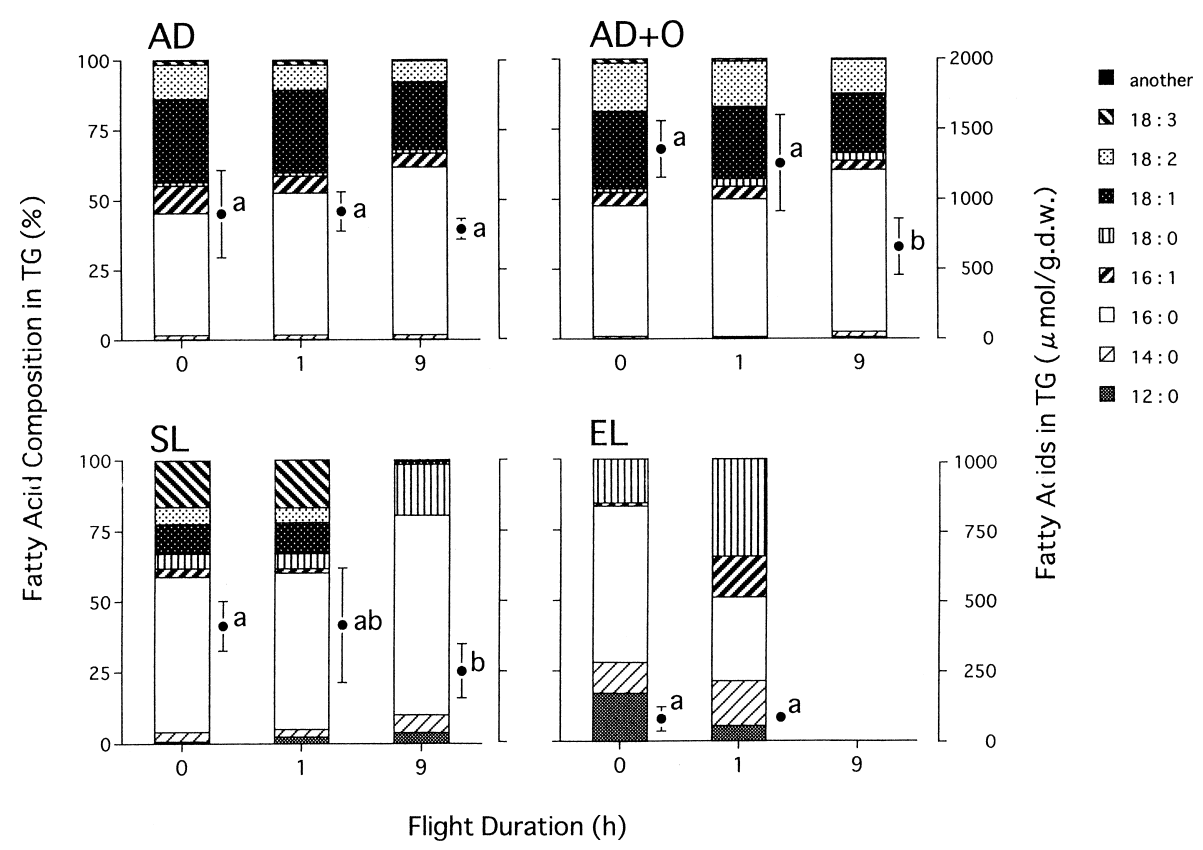

Fig. 3. Changes in TG levels $(\bullet)$ and their fatty acid composition during tethered flight in the abdomens of 3-day-old non-fed $S$. litura males, which were fed during the last larval instar on one of the four diets (see Fig. 1). Values of TG content (average \pm SD, $N=5)$ with different letters are significantly different $(p<0.05, U$-test).

acid during flight in the TG of both groups. On the other hand, in the case of the males from SL, linolenic acid, which comprised $17 \%$ of the TG fatty acids before flight, disappeared and the ratio of $\mathrm{C} 18$ unsaturated fatty acids declined from 33\% to only $3 \%$. In all three of these groups of male adults, palmitic acid (C16:0) was the predominant component of abdominal TG's and its ratio in the TG's tended to increase with longer flights. The male adults derived from EL had essentially no C18 unsaturated fatty acids in their abdominal TG (Fig. 3).

\section{DISCUSSION}

The effect of fatty acids on flight activity has been studied in only a few insect species. Arachidonic acid (C20:4) is an essential nutrient for mosquitos, Culex pipiens, and the lack of this fatty acid in their larval diet causes the adults to be flightless (Dadd and Kleinjan, 1979; Dadd et al., 1986). The larvae of beetles, Rhyzopertha dominica reared on cereal rice and wheat emerge as adults with higher flight initiation, higher lipid content and higher oleic acid concentration than those reared on corn and sorghum (Perez-Mendoza et al., 1999). The adults of the diamondback moth,
Plutella xylostella fed on wild crucifers as larvae have higher flight activity (Muhamad et al., 1994; Begum et al., 1996) and tend to have higher levels of TG than those fed on cultivated cabbage (Begum et al., 1999).

Itoyama et al. (1999) demonstrated that $S$. litura individuals developed more slowly to smaller adults with smaller wing loading indices and lower abdominal TG levels, although fatty acid composition in the TG was not different, when the last instar larvae were fed on the artificial diet used in the present study but of lower quality. Those from the diet of lower quality were seemingly inferior in flight capability. Here, we further showed that the addition of soybean oil $(0.03 \% \mathrm{w} / \mathrm{w})$ (in which linoleic acid is predominant, followed by oleic acid) to the diet, greatly increased the level of abdominal TG, but did not change the fatty acid composition in the TG in the male moths (Fig. 1). The addition did not cause significant differences in either developmental profiles (Table 1), or total flight duration (Fig. 2). Thus, it can be said that flight capability is not enhanced by larval feeding on a diet containing soybean oil, at least for the duration of the tethered flight tested for a maximum of $20 \mathrm{~h}$. This may be caused by a shortage of some of the nutrients required to continue burning fuel or by 
factors restricting flight ability such as the physiological capability of flight muscles to burn the lipids.

Another study (Murata and Tojo, in press) demonstrated the decline of TG levels and also the ratio of unsaturated fatty acids in TG's with longer durations of tethered flight in three-day-old male adults of $S$. litura from AD fed larvae, which coincided with the present results (Fig. 3). Flight duration and the tendency of $\mathrm{C} 18$ unsaturated fatty acids to decrease during flight, did not differ greatly among the adults from $\mathrm{AD}, \mathrm{AD}+\mathrm{O}$ or $\mathrm{SL}$ fed larvae. Adults in these three groups contained abdominal TG with $30-40 \%$ unsaturated fatty acids in its fatty acids, but the fatty acid composition in TG differed greatly between those from AD $(\mathrm{AD}+\mathrm{O})$ and SL (Fig. 3). These results support TG unsaturated fatty acid level, but not its fatty acid composition is one of the major factors influencing flight capability. Adults from SL almost exhausted the unsaturated fatty acids in the TG, but retained TG at $250 \mu \mathrm{mol} / \mathrm{g}$ d.w. nine hours after tethered flight, and some individuals tested could fly for over $16 \mathrm{~h}$ (Figs. 2 and 3). These results support the notion that unsaturated fatty acids are utilized first followed by the saturated fatty acids in the TG during flight.

The stocks of $S$. litura used in the present study had been reared on the artificial diet, i.e., AD for several years and so they are expected to be highly adapted to AD. However, the individuals reared on soybean leaves (SL) tended to grow faster than those from $\mathrm{AD}$, as reflected in the higher emergence ratio, but they grew into smaller pupae and adults with a smaller wing loading index (Table 1). This fact may exclude the possibility that the growing differences among $S$. litura reared on the four diets are due to previous feeding experiences. Unexpectedly large differences were found not only in developmental profiles, but also in adult characteristics, when the last instar larvae of $S$. litura were reared on SL and EL. The males from EL emerged as adults with smaller bodies at a lower survival ratio after their development had been significantly retarded (Tables 1 and 2). The males had far lower levels of TG with essentially no unsaturated fatty acids (Fig. 3). The eddo leaves had similar levels of total fatty acids, but with a higher ratio of unsaturated fatty acids, compared with soybean leaves (Fig. 1). The mechanism leading to adults with low levels of TG and low ratios of unsaturated fatty acids in TG's as result of feeding as larvae on eddo leaves with a high total fatty acid content rich in unsaturated fatty acids needs to be elucidated.

The low flight ability of adults from EL was possibly brought about by low TG and also by the absence of unsaturated fatty acids in the TG (Figs. 2 and 3). Based on these results, eddo is not considered to be a good feeding plant for $S$. litura, and the moths that feed on eddo, even if they are raised on this plant, are not expected to be involved in dispersal and migration. We also conclude that the migration capability of $S$. litura is largely influenced by the feeding plants.

\section{ACKNOWLEDGEMENTS}

We would like to thank Makoto Hatakoshi of Sumitomo Chemical Co., Ltd. for supplying the $S$. litura eggs and to Takayuki Kashima and Yuka Kawahira of our laboratory for their help in the lipid analysis. This work was partly supported by a Grand-in-Aid from the Japan Society for the Promotion of Science (No. 13460023).

\section{REFERENCES}

Asahina, S. and Y. Turuoka (1968) Records of the insects visited a weather ship located at the Ocean Weather Station 'Tango' on the Pacific II. Kontyu 36: 190-202 (in Japanese).

Awmack, C. S. and S. R. Leather (2002) Host plant quality and fecundity in herbivorous insects. Annu. Rev. Entomol. 47: 817-844.

Beenakkers, A. M. Th., D. J. Van der Horst and W. J. A. Van Marrewijk (1985) Insect lipids and lipoproteins, and their role in physiological processes. Prog. Lipid Res. 24: 19-67.

Begum, S., R. Tsukuda, K. Fujisaki and F. Nakasuji (1996) The effects of wild cruciferous host plants on morphology, reproductive performance and flight activity in the diamondback, Plutella xylostella (Lepidoptera: Yponomeutidae). Res. Popul. Ecol. 38: 257-263.

Begum, S., R. Tsukuda, H. Tsumuki, K. Fujisaki and F. Nakasuji (1999) Comparison of flight fuel and other nutrients in the diamondback moths, Plutella xylostella grown on a wild host and cabbage. Entomol. Sci. 2: 13-19.

Blacklock, B. J. and R. O. Ryan (1994) Hemolymph lipid transport. Insect Biochem. Mol. Biol. 24: 855-873.

Dadd, R. H. and J. E. Kleinjan (1979) Essential fatty acid for the mosquito Culex Pipiens: arachidonic acid. J. Insect Physiol. 25: 495-502.

Dadd, R. H., J. E. Kleinjan and D. W. Stanley-Samuelson (1986) Polyunsaturated fatty acids of mosquitos reared with single dietary polysaturates. Insect Biochem. 17: $7-16$.

Harrison, R. G. (1980) Dispersal polymorphism in insects. Ann. Rev. Ecol. Syst. 11: 95-118.

Itoyama, K., Y. Kawahira, M. Murata and S. Tojo (1999) 
Fluctuations of some characteristics in the common cutworm, Spodoptera litura (Lepidoptera: Noctuidae) reared under different diets. Appl. Entomol. Zool. 34: 315-321.

Muhamad, O., R. Tsukuda, Y. Oki, K. Fujisaki and F. Nakasuji (1994) Influences of wild crucifers on life history traits and flight ability of the diamondback moth, Plutella $x y$ lostella (Lepidoptera: Yponomeutidae). Res. Popul. Ecol. 36: 53-62.

Murata, M., T. Etoh, K. Itoyama and S. Tojo (1998) Sudden occurrence of the common cutworm, Spodoptera litura (Lepidoptera: Noctuidae) in southern Japan during the typhoon season. Appl. Entomol. Zool. 33: 419-427.

Murata, M. and S. Tojo Flight capability and saturated fatty acid level in triacylglycerol of long-distance migratory adults of the common cutworm, Spodoptera litura. Zool. Sci. (in press).

Okamoto, D. and T. Okada (1968) Studies on the tobacco cutworm, Prodenia litura Fabricius, as an insect pest of the forage crops. Bull. Chugoku Natl. Agric. Exp. Stn. E2: 111-141 (in Japanese).

Perez-Mendoza, J., B. A. Dover, D. W. Hagstrum and T. L. Hopkins (1999) Effect of crowding, food deprivation, and diet on flight initiation and lipid reserves of the lesser grain borer, Rhyzopertha dominica. Entomol. Exp. Appl. 91: 317-326.

Slansky, F., Jr. and J. M. Scriber (1985) Food consumption and utilization. In Comprehensive Insect Physiology, Biochemistry and Pharmacology. Vol. 4 (G. A. Kerkut and L. I. Gilbert eds.). Pergamon Press, Oxford, pp. 88-163. 